\title{
Naltrexone has no effects on body weights of starving rats
}

\author{
LARRY D. REID and JANUSZ WIDEMAN \\ Department of Neuropharmacology \\ Max-Planck-Institut für Psychiatrie, D-8000 Munich 40, West Germany
}

\begin{abstract}
Thirty rats (10 rats/group) were fixed with devices for the chronic delivery of naltrexone (1.2 or $2.4 \mathrm{mg} / \mathrm{rat} /$ day) or saline. Then, they were subjected to deprivation of food and water for 4 days, during which their body weights were measured twice daily. The rats with naltrexone lost body weight at rates very similar to those of rats receiving saline. This observation is at variance with recent formulations concerning the ordinary functions of the endorphins. Naltrexone suppressed water and food intakes when food and water were presented after the 96-h starvation period.
\end{abstract}

Margules (1979) has put forth the intriguing idea that the endorphins play a special role in conserving nutrients and suppressing energy-spending activity when an individual is suffering famine. Also, Margules' theory was used in the theorizing of Reid and Siviy (in press). In brief, these ideas concerning the ordinary functions of the endorphins contend that starvation leads to a complex set of endorphinergic-related events including seeking food, conserving energy by suppression of sexuality and general activity, retaining food in the gut, and retaining ions such as sodium and calcium.

A simple test of the idea that the endorphins function to conserve nutrients during starvation is to chronically block the opioid receptors with an antagonist such as naloxone or naltrexone and observe body-weight loss as a function of food and water deprivation. There is, however, a technical problem associated with such a test. Although naltrexone is a long-acting antagonist and in the human being provides antagonistic action for up to $24 \mathrm{~h}$ in doses producing few side effects, in the rat, even large doses, such as $10 \mathrm{mg} / \mathrm{kg}$ subcutaneously, are not sufficient to provide 24-h suppression of eating and drinking when given once daily (Merriman, 1981). In brief, although naltrexone has a long-lasting effect, it is difficult to maintain chronic antagonism by way of injections. A solution to the technical problem is to give naltrexone by way of an ALzet ${ }^{\circledR}$ minipump, an indwelling device for releasing small quantities of drug continuously across days, thereby ensuring a constant high-level antagonism. Consequently, we measured weight loss in rats suffering from food and water depri-

We thank Albert Herz for arranging for the facilities to do this work and for discussions with him concerning the implications of these data. L. D. Reid is also affiliated with the Department of Psychology, Rensselaer Polytechnic Institute, Troy, New York. Janusz Wideman is also affiliated with the Department of Neurochemistry, Medical Research Center of the Polish Academy of Sciences, Warsaw, Poland. vation that were given naltrexone chronically by way of minipumps.

\section{METHOD}

Thirty rats ( 10 rats/group) provided the data to be presented here. They were all Sprague-Dawley-derived males acquired from a local supplier (IWV, Gelting, West Germany) shortly before the procedures began.

The rats were housed in wire-mesh and plastic cages, $55 \mathrm{x}$ $34 \times 18 \mathrm{~cm}$, on sawdust, in groups of $10 \mathrm{rats} / \mathrm{cage}$. The cages were in a room maintained on a 12-h-on, 12-h-off daily light cycle, with lights on at $0800 \mathrm{~h}$. The room was maintained at $24^{\circ} \mathrm{C}-25^{\circ} \mathrm{C}$ and about $40 \%$ humidity.

After rats were habituated to the housing conditions and daily handling (i.e., after they were eating the vast majority of their food at night, were gaining weight across days, and did not defecate upon being weighed), they were placed on a starvation schedule. Starvation was 4 days without food and water.

Before, during, and after starvation, rats were weighed twice daily, once just before lights went on and once just before lights went off. On the morning of the beginning of starvation, each rat was anesthetized with ether and a minipump was inserted under the skin of the upper back. The pumps of one group were loaded with saline, and the pumps of the other two groups were loaded with naltrexone $\mathrm{HCl}$ in saline.

There were two doses of naltrexone. One set of pumps delivered $1.2 \mathrm{mg} / \mathrm{rat} / \mathrm{day}$, and one delivered $2.4 \mathrm{mg} / \mathrm{rat} / \mathrm{day}$. At the beginning of starvation, these doses were a mean of 4.5 and $8.9 \mathrm{mg} / \mathrm{kg}$ of body weight per day. The pumps are designed to provide constant infusion for greater than 6 days. Since naltrexone is long lasting and since naltrexone was infused constantly, the rats were constantly under the influence of relatively high levels of naltrexone throughout starvation and the day immediately following it.

At the end of the 4 days of starvation, four rats of each group were given a $10-\mathrm{mg} / \mathrm{kg}$ dose of morphine $\mathrm{HCl}$, subcutaneously. Twenty minutes later, analgesia was measured by the tail-flick method using radiant heat to the tail as the putative aversive stimulus. This procedure was done to confirm that the rats receiving naltrex one were indeed receiving it.

The other rats of each group were given food and water, after being transferred to individual cages in the same colony room, and their intakes were observed at the end of $.5,1,12$, and $24 \mathrm{~h}$; body weights were taken at 12 and $24 \mathrm{~h}$ after food and water presentation. 


\section{RESULTS AND DISCUSSION}

Young adult rats given food and water under these conditions gained weight during the night, lost some across the day, and added weight in small amounts daily. Rats somewhat smaller than those used in this experiment, but housed and handled under very similar conditions, suffered 3 days of food and water deprivation. They lost $10.3 \%, 17.2 \%$, and $22.6 \%$ of their prestarvation body weights (mean $=229.4 \mathrm{~g}$ ) in 24,48 , and $72 \mathrm{~h}$, respectively. Since the percentage of weight loss was actually slightly smaller in the rats of this experiment, which received surgery for installing the pumps, than in this other, similar group, it is concluded that the surgery itself was of little consequence to the weight loss seen in the subjects of this experiment.

The rats having surgery to install the minipumps but getting saline lost $8.4 \%, 14.3 \%, 16.1 \%$, and $22.9 \%$ of the body weight seen just before starvation (mean = $347.8 \mathrm{~g}$ ) in $24,48,72$, and $96 \mathrm{~h}$, respectively. The rats receiving naltrexone lost very similar amounts with starvation.

An analysis of variance (ANOVA) of the 30 rats' body weights during the period of starvation was done (a 3 by 9 factorial design having repeated measures and a factor associated with doses of naltrexone and nine measures of body weight, including the last weight measure before starvation and a weight measure for each $12 \mathrm{~h}$ across 4 days). The factor associated with continuance of starvation was, of course, a reliable source of variance $(p<.01)$, but the factor associated with doses of naltrexone $(0,1.2$, and $2.4 \mathrm{mg} / \mathrm{rat} /$ day $)$ was not $[\mathrm{F}(2,27)=.2, \mathrm{p}=.85]$ and the interaction term was not $[F(5,216)=1.2, p=.24]$. It is concluded, therefore, that naltrexone is without effect on body weights as a function of starvation; for example, the subjects receiving saline lost $78.8 \mathrm{~g}$, whereas rats receiving the lower and higher doses of naltrexone lost 74.6 and $78.4 \mathrm{~g}$, respectively, across $96 \mathrm{~h}$ of deprivation.

Subsequent to the starvation period, each rat of the saline group receiving morphine showed analgesia (mean seconds to tail flick $=14.5 \mathrm{sec}$, with a $15 \mathrm{sec}$ cutoff), whereas none of the rats in the group receiving chronic naltrexone showed signs of analgesia (mean = $6 \mathrm{sec}$ ). A group of five rats, having no other part in these procedures and receiving no drugs, were tested concomitantly and showed tail-flick latencies similar to those of subjects receiving naltrexone and morphine $($ mean $=5 \mathrm{sec})$. The $t$ for the difference between subjects receiving morphine and naltrexone and those receiving morphine and saline was $t(11)=16.4(p<.01)$. These results plus those given below with respect to water intake confirm that the rats with naltrexone in their pumps were indeed under the influence of naltrexone.

The rats given food and water ( $n=6 /$ group) after the deprivation started drinking and eating immediately when given the opportunity. As can be seen from Table 1, however, rats under the influence of naltrexone
Table 1

\begin{tabular}{ccccc}
\hline \multirow{2}{*}{$\begin{array}{c}\text { Dose of } \\
\text { Naltrexone }\end{array}$} & \multicolumn{4}{c}{ Postadministration Interval (in Hours) } \\
\cline { 2 - 5 } & .5 & 1 & 12 & 24 \\
\hline \multicolumn{5}{c}{ Mean Water Intake (in Grams) } \\
.0 & 10.5 & 16.3 & 38.4 & 56.5 \\
1.2 & $6.8^{*}$ & $10.1^{*}$ & $31.1^{*}$ & $46.3^{*}$ \\
2.4 & $5.8^{*}$ & $9.1^{*}$ & $31.0^{*}$ & $45.6^{*}$ \\
& Mean Food Intake (in Grams) & \\
.0 & 3.0 & 6.1 & 18.6 & 28.1 \\
1.2 & 2.6 & 4.8 & 17.3 & 25.8 \\
2.4 & 2.4 & $4.0^{*}$ & 15.4 & 23.6 \\
\hline
\end{tabular}

${ }^{*} p<.01$ for comparison between scores of saline controls (.0 mg/day) and those of a dose of naltrexone achieved following an ANOVA and using Dunnett's test for comparing values to a control value.

drank and ate less than the rats receiving saline. With these rats, there was $96 \mathrm{~h}$ of deprivation and yet there was a clear suppression of drinking with naltrexone. This observation confirms the conclusion of Ostrowski, Foley, Lind, and Reid (1980) that strong deprivation will not abolish the opioid-antagonist effect on fluid intake.

Given that rats under naltrexone drink and eat less after presentation of food and water, it would be expected that they would gain less weight. This was the case: After $12 \mathrm{~h}$ of opportunity to feed and drink, rats receiving saline gained $33.3 \mathrm{~g}$ and rats receiving naltrexone gained 26.4 and $26.5 \mathrm{~g}$ for the low and high doses, respectively $[\mathrm{F}(2,15)=8.9, \mathrm{p}<.01]$. A 3 by 3 ANOVA, having repeated measures with one factor for the groups and one factor for the last weight of starvation and weights of 12 and $24 \mathrm{~h}$ after food and water presentation, confirms the observation of differential weight gain by yielding a reliable effect associated with the factor of the interaction $[F(5,30)=4.1, p<.01]$.

These data provide no support for the portion of the theories of endorphin function (Margules, 1979; Reid \& Siviy, in press) that postulate a role of the endorphins in conservation of nutrients, and hence body weight, with starvation. These data are irrelevant to other portions of those theories, and incidentally, there is mounting evidence to support a generalization that the endorphins are related to the regulation of eating and drinking. For example, naltrexone diminished drinking even after 96-h deprivation and the opportunity for there to be tolerance to naltrexone because of its continued presence across the $96 \mathrm{~h}$. There are, however, compensatory mechanisms with respect to eating and drinking (tolerance?) when guinea pigs are chronically under the influence of an opioid antagonist and have food and water always available within 4 days (Schulz, Wüster, \& Herz, 1980).

As a consequence of the data presented here, we think the theories should be amended by deleting those parts stating that one of the ordinary functions of the endorphins is to conserve nutrients in the face of starva- 
tion. A consequence of such an amendment is that we are without extant ideas in the literature concerning the role of the endorphins in the gut with respect to the coordinated, adaptive functioning of the organism. Perhaps gut endorphins are part of the mechanism preparing the gut, sequentially, to receive nutrients subsequent to their intake.

\section{REFERENCES}

Margules, D. L. Beta-endorphin and endoloxone: Hormones of the autonomic nervous system for the conservation or expenditure of bodily resources and energy in anticipation of famine or feast. Neuroscience and Biobehavioral Reviews, 1979, 3, 155-162.

Merriman, J. V. The effects of chronic endorphin blockade on feeding, drinking and intracranial self-stimulation. Unpublished master's thesis. Rensselaer Polytechnic Institute, Troy, New York, 1981.

Ostrowski, N. L., Foley, T. L., Lind, M. D., \& Reid, L. D. Naloxone reduces fluid intake: Effects of water and food deprivation. Pharmacology, Biochemistry and Behavior, 1980, 12, 431-435.

REID, L. D., \& Siviy, S. M. Administration of antagonists of morphine and endorphin reveal endorphinergic involvement in reinforcement processes. In J. E. Smith \& J. D. Lane (Eds.), Neurobiology of opiate reward mechanisms. Amsterdam: Elsevier/North-Holland, Biological Medical Press, in press.

Schultz, R., Wüster, M., \& HERz, A. Interactions of amphetamine and naloxone in feeding behavior in guinea pigs. European Journal of Pharmacology, 1980, 63, 313-319.

(Received for publication February 20, 1982.) 